\title{
Venous thromboembolism in non-small cell lung cancer patients: retrospective analysis of cases treated at the Oncology Day Hospital of Novara, Italy
}

\author{
Roberta Buosi, ${ }^{1}$ Gloria Borra, ${ }^{1}$ Oscar Alabiso, ${ }^{1}$ Alessandra Galetto, ${ }^{1}$ Giovanni Pappagallo, ${ }^{2}$ Mauro Campanini ${ }^{3}$ \\ ${ }^{1}$ SCDU Oncologia Medica, AOU Maggiore della Carità, Novara; ${ }^{2}$ Servizio di Statistica ed Epidemiologia dei Tumori, \\ Dipartimento di Scienze Mediche, Padova; ${ }^{3} \mathrm{SC}$ Medicina Interna, AOU Maggiore della Carità, Novara, Italy
}

\begin{abstract}
Venous thromboembolism (VTE) is the leading cause of mortality and morbidity in patients with cancer. The estimated risk of VTE in cancer patients is $0.5 \%$ per year and $0.04 \%$ per month. In small cell lung cancer and non-small cell lung cancer (NSCLC) the cumulative incidence is $3 \%$ per year and it seems to be associated with advanced stage and histotype. We performed a retrospective analysis on data from all NSCLC treated at the Oncology Day Hospital in Novara, Italy, northern Italy, to assess the incidence of thromboembolic events in patients undergoing systemic cancer treatments. All patients diagnosed with NSCLC who were treated at the Oncology Day Hospital in Novara from January 2008 to May 2011 have been assessed. Many variables related to VTE were analyzed: age, gender, different NSCLC histotype, Eastern Cooperative Oncology Group (ECOG) performance status, body mass index, stage of disease, treatment and chemotherapy regimen, development of a VTE event and its temporal correlation with chemotherapy, central venous catheter presence, use of erythropoietin, use of low molecular weight heparin at baseline, use of acetyl salicylic acid. A total of 355 patients were evaluated, 307 of whom were considered to be eligible for analysis. Median age was 68 years. Histology was as follows: $7 \%$ not otherwise specified, $60 \%$ adenocarcinoma, $31 \%$ squamous cell carcinoma and $2 \%$ large cell carcinoma. Thirty-six cases of deep vein thrombosis (DVT) have been reported (incidence $12 \%$ ). Thirty-one DVT were recorded in patients who were candidates for or undergoing chemotherapy: 14 during treatment, 7 at the end of chemotherapy, and 10 before treatment. The incidence was significantly higher for patients treated with cisplatin (CDDP), both during chemotherapy and after chemotherapy. A correlation with disease stage was documented: $26.5 \%$ of total VTE occurred in locally advanced and metastatic stages (IIIB and IV); $18.8 \%$ in stage IIIA (N2). A significant correlation between non-squamous histology was also highlighted ( $\mathrm{P}=0.015)$ and ECOG 0-1 $(\mathrm{P}=0.010)$. According to the high incidence of VTE in patients with NSCLC, especially adenocarcinoma, and the correlation highlighted in this study with ECOG performance status 0-1 and CDDP-based treatment, we believe that outpatients undergoing chemotherapy for advanced stage (IIIB-IV) lung cancer should receive thromboembolic prophylaxis at least for the duration of chemotherapy. It is, therefore, essential to propose a thrombo-prophylaxis clinical trial that recruits only lung cancer patients to evaluate the benefit of prophylaxis in this population and to assess the real risk of bleeding during antithrombotic treatment.
\end{abstract}

Correspondence: Roberta Buosi, DH Oncologico, AOU Maggiore della Carità, C.so Mazzini 18, 28100 Novara, Italy. Tel. +39.338.1185705.

E-mail: r.buosi@maggioreosp.novara.it

Key words: non small-cell lung cancer, thromboembolism events, outpatients.

Conflict of interests: the authors have no potential conflict of interests.

This work is licensed under a Creative Commons Attribution NonCommercial 3.0 License (CC BY-NC 3.0).

CCopyright R. Buosi et al., 2013

Licensee PAGEPress, Italy

Italian Journal of Medicine 2013; 7:113-117

doi:10.4081/itjm.2013.113

\section{Introduction}

Venous thromboembolism (VTE) is the leading cause of mortality and morbidity in patients with cancer. It can delay or interfere with the cancer therapy and, therefore, it can be associated with a significant impact on quality of life. In Stein's study, ${ }^{1}$ VTE incidence in the general population of hospitalized patients is stable but is increased in the group of cancer patients. In fact, the estimated risk of VTE is $0.5 \%$ per year and $0.04 \%$ per month. VTE consists of two major clinical conditions: deep vein thrombosis (DVT) and pulmonary embolism (PE). These events can be the first clinical manifestation of an occult malignancy or develop in different stages of cancer. VTE risk in cancer patients is a dynamic process: higher at diagnosis, during chemotherapy and at progression, lower during remission. ${ }^{2-4}$ Some retrospective studies have shown that $15 \%$ of cancer patients develop a symptomatic thromboembolism and that it adversely affects prognosis: one out of 7 patients die because of a VTE 
event, and only $12 \%$ of patients with cancer-associated VTE survive beyond one year after this event. ${ }^{5-9}$

Specifically concerning neoplastic lung disease, Chew et al. ${ }^{10,11}$ reports a one-year cumulative incidence of 3\% in patients with small cell lung cancer and nonsmall cell lung cancer (NSCLC) at any stage of disease, and the strong evidence of the predictive value of VTE for advanced clinical stage. Primary cancer site and stage of disease greatly affect the risk of VTE. In a retrospective cohort study, the highest incidences of VTE have been reported for pancreatic cancer $(12.1 \%)$, brain $(9.5 \%)$, uterus $(9 \%)$, kidney $(7.6 \%)$ and stomach (7.4\%). In lung cancer, the association between VTE and histology is known. ${ }^{10} \mathrm{~A}$ higher risk of thromboembolic events has been reported in adenocarcinoma histotype. A higher VTE risk related to the type of chemotherapy administered was also observed. ${ }^{11-16}$

Therefore, we decided to carry out a retrospective analysis of data on all NSCLC cases followed at the Oncology Day Hospital in Novara, northern Italy, to evaluate the incidence of thrombo-embolic events in outpatients receiving active treatment.

\section{Materials and Methods}

The analysis was performed by evaluating all patients diagnosed with NSCLC who were treated at the Oncology Day Hospital of the Maggiore della Carità Hospital, Novara, northern Italy, from January 2008 to May 2011.

Patients' characteristics analyzed as variables associated with VTE were: age, sex, different NSCLC histotype, Eastern Cooperative Oncology Group (ECOG) performance status, body mass index (BMI), stage of disease, treatment and chemotherapy regimen, development of a VTE event and its temporal correlation with chemotherapy, central venous catheter presence, use of erythropoietin, use of low molecular weight heparin (LMWH) at baseline, use of acetyl salicylic acid.

For thromboembolic events we considered: i) symptomatic DVT, confirmed by echocolordoppler or computed tomography (CT); ii) symptomatic PE, confirmed by $\mathrm{CT}$ or pulmonary angiography; iii) asymptomatic DVT, diagnosed by echocolordoppler or CT; iv) asymptomatic $\mathrm{PE}$, diagnosed by $\mathrm{CT}$ or pulmonary angiography.

Variables were distributed over an interval scale and were represented by median and interquartile distance. The variables of a qualitative nature have been described by absolute and relative frequency.

Contingency tables were analyzed using Pearson's $\chi^{2}$ test. $\mathrm{P}$ values refer to the two-tailed $\chi^{2}$ distribution.

\section{Results}

We collected the data of 355 patients with median age 68 years old (range 31-84 years). Forty-eight pa- tients were not included in the stratified analysis for small cell lung cancer histological type. Of the 307 remaining patients, $21(7 \%)$ were classified as not otherwise specified, $186(60 \%)$ as adenocarcinoma, 5 $(2 \%)$ as large cell carcinoma and $95(31 \%)$ were classified as squamous-cell carcinoma.

Patients' characteristics are summarized in Table 1. Thirty-six cases of DVT were registered in the entire study population, corresponding to an incidence of $12 \%$.

Thirty-one events were reported in patients treated with chemotherapy, and specifically, 14 cases occurred during treatment, 7 at the end of therapy and 10 before beginning therapy.

The 21 DVT events that occurred during and at the end of therapy were classified according to the therapy regimen administered; the incidence of the DVT events was significantly superior in patients treated with cisplatin in agreement with the literature data ${ }^{11,12}$ (Table 2).

A correlation between tumor stage and VTE incidence was documented: $26.5 \%$ were locally advanced and metastatic stages tumor lung (IIIB-IV) and 18.8\% were $\mathrm{N} 2$ positive patients (IIIA). A statistically significant correlation was also evident between VTE and non-squamous cell carcinoma histotype, $\mathrm{P}=0.015$, and there was correlation with ECOG $0-1, \mathrm{P}=0.010$.

There was no significant correlation with age, gender, BMI, central venous system (CVS), or other type risk (Table 3).

\section{Discussion}

All patients were treated at the Oncology Day Hospital of Novara; no patient was hospitalized. In our retrospective study, we analyzed 355 patients with lung cancer: 307 were non-small-cell lung cancer, $60 \%$ of those were adenocarcinoma and $31 \%$ were squamous cell carcinoma.

Out of 307 patients we registered 36 cases of VTE (12\%); 21 occurred during therapy.

Most patients had a stage IV disease and an ECOG performance status (PS) of $0-1$. Therefore, $70 \%$ of the patients received an antineoplastic treatment, often a platinum-based regimen. The presence of metastatic disease was strongly associated with an increased risk of VTE. An analysis of the California Cancer Registry found that the $56 \%$ of patients with VTE had metastatic disease compared with $21 \%$ of patients without VTE. Therefore, the patients with stage IV cancer at the time of diagnosis had a 1.4-fold to 21.5-fold higher risk of thromboembolism than patients with locally advanced cancer.

The analysis of the data found a correlation between the thromboembolism events and histology $(\mathrm{P}=0.015)$, but there was no correlation with any other risk factors (age, gender, BMI, stage or CVS). The patients with adenocarcinoma have a higher risk of VTE 
compared with those with squamous cell carcinoma, as reported by Chew et al. ${ }^{10}$

Concerning gender, it is important to note that only $20 \%$ of the study population were females, given that lung cancer is more frequent in men than in women, although the incidence in females has increased over the last ten years.

In addition, we did not observe a higher risk of

Table 1. Patients' characteristics.

\begin{tabular}{lc}
\hline & Number $(\%)$ \\
\hline Patients' characteristics & \\
Median age (range) & $68(31-84$ years), distance-IQ 14 \\
$>65$ years & $58 \%(177)$ \\
Male & $80 \%(245)$ \\
Female & $20 \%(62)$ \\
Adenocarcinoma & $60 \%(186)$ \\
Squamous-cell carcinoma & $31 \%(95)$ \\
Large-cell carcinoma & $2 \%(5)$ \\
NOS & $7 \%(21)$
\end{tabular}

$74 \%(226)$

$12 \%(38)$

$9 \%(29)$

$5 \%(14)$

3

\section{TNM stage}

I $\quad 2 \%(7)$

II

IIIa

IIIb

IV

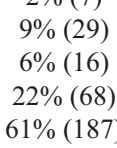

\section{BMI}

$<25 \%$

$>25 \%$

N.D.

$69 \%(153)$

$31 \%(70)$

(84)

\begin{tabular}{lc}
\hline Chemotherapy & \\
Yes & $70 \%(215)$ \\
No & $30 \%(92)$ \\
\hline CVS & \\
Yes & $16 \%(46)$ \\
No & $84 \%(260)$ \\
N.D. & $(1)$ \\
\hline
\end{tabular}

\section{Past DVT}

$\begin{array}{lc}\text { Yes } & 5 \%(16) \\ \text { No } & 95 \%(291)\end{array}$

Erythropoiesis-stimulating drugs

$\begin{array}{lc}\text { Yes } & 2 \%(7) \\ \text { No } & 98 \%(300)\end{array}$

\section{Baseline LMWH}

$\begin{array}{lc}\text { Yes } & 13 \%(39) \\ \text { No } & 87 \%(268)\end{array}$

\section{Ongoing ASA}

Yes $81 \%(249)$

No $19 \%(58)$

IQ, interquartile; NOS, not otherwise specified; ECOG, Eastern Cooperative Oncology Group; PS, performance status; TNM stage: T, tumor size, N, lymphonodes, M, metastasis; BMI, body mass index; N.D., not detected; CVS, central venous system; DVT, deep vein thrombosis; LMWH, low molecular weight heparin; ASA, acetyl salicylic acid.
VTE in the patients with CVS, in contrast to reports in the literature. ${ }^{17-19}$

We think that the correlation of VTE with CVS is not evident because of insufficient data, as only $16 \%$ (48 of 307) of the patients had CVS.

Moreover, we remember that in recent cases the incidence of VTE for every type and every stage of lung cancer has only been $3 \% .^{10,11}$

Table 2. Deep vein thrombosis cases according to chemotherapy regimen administered.

\begin{tabular}{lcc}
\hline Chemotherapy regimen & During & $\begin{array}{c}\text { DVT } \\
\text { End of therapy }\end{array}$ \\
\hline Pemetrexed+CDDP & 1 & 1 \\
\hline Gemcitabine+CDDP & 7 & 5 \\
\hline Vinorelbine & 1 & 1 \\
\hline Bevacizumab+CDDP+paclitaxel & 1 & - \\
Bevacizumab+pemetrexed+CDDP & 1 & - \\
Erlotinib & 3 & - \\
\hline DVT, deep vein thrombosis; CDDP, cisplatin & &
\end{tabular}

DVT, deep vein thrombosis; CDDP, cisplatin.

Table 3. Deep vein thrombosis incidence correlation with different characteristic of baseline variables.

\begin{tabular}{|c|c|c|}
\hline Variable & DVT (incidence \%) & Pvalue \\
\hline \multicolumn{3}{|l|}{ Gender } \\
\hline Male & $26 / 245(10.6 \%)$ & \multirow{2}{*}{0.228} \\
\hline Female & $10 / 62(16.1 \%)$ & \\
\hline \multicolumn{3}{|l|}{ Age } \\
\hline$<65$ years & 16/121 (13.2\%) & \multirow{2}{*}{0.511} \\
\hline$\geq 65$ years & $20 / 186(10.8 \%)$ & \\
\hline \multicolumn{3}{|l|}{ Histotype } \\
\hline Non-squamous & $26 / 245(15.7 \%)$ & \multirow{3}{*}{0.015} \\
\hline Squamous & 6/95 (6.3\%) & \\
\hline NOS & 0/21 (-) & \\
\hline \multicolumn{3}{|l|}{ ECOG } \\
\hline $0-1$ & $36 / 264(13.6 \%)$ & \multirow{2}{*}{0.010} \\
\hline $2-3$ & 0/43 (-) & \\
\hline \multicolumn{3}{|l|}{ BMI } \\
\hline$<25$ & $22 / 152(14.5 \%)$ & \multirow{2}{*}{0.938} \\
\hline$\geq 25$ & $10 / 71(14.1 \%)$ & \\
\hline \multicolumn{3}{|l|}{ Stage } \\
\hline I-II & $1 / 36(2.8 \%)$ & \multirow{4}{*}{0.248} \\
\hline IIIA & $3 / 16(18.8 \%)$ & \\
\hline IIIB & $10 / 68(14.7 \%)$ & \\
\hline IV & $22 / 187(11.8 \%)$ & \\
\hline \multicolumn{3}{|l|}{ CVS } \\
\hline No & $29 / 260(11.2 \%)$ & \multirow{2}{*}{0.685} \\
\hline Yes & 7/46 (15.2\%) & \\
\hline \multicolumn{3}{|l|}{ ASA } \\
\hline No & 27/249 (10.8\%) & \multirow{2}{*}{0.938} \\
\hline Yes & 9/58 (15.5\%) & \\
\hline
\end{tabular}

DVT, deep vein thrombosis; NOS, not otherwise specified; ECOG, Eastern Cooperative Oncology Group; BMI, body mass index; CVS, central venous system; ASA, acetyl salicylic acid. 
Our retrospective study has demonstrated a strong correlation of VTE with non-squamous histology. In fact, 29 patients with VTE had an adenocarcinoma and only 6 a squamous cell carcinoma of the lung. But the most interesting data show that the thromboembolic risk is highest in ECOG 0-1 patients (13.6\%) and this is statistically significant $(\mathrm{P}=0.010)$. The explanation for this is that the patients with the best PS and without comorbidities received full-dose chemotherapy and platinum-based regimens.

In contrast with reports in the literature, we did not see any correlation with erythropoiesis-stimulating agents, so we can not prove that erythropoietin increases the risk of VTE. In fact, no patient treated with these drugs experienced a thromboembolism. ${ }^{20,21}$ From a meta-analysis by Bohlius it seems evident that treatment with epoetin or darboepoetin increased the risk of VTE by approximately $67 \%$ compared to patients without this treatment. But new data demonstrated that the VTE events are observed in patients with an increase in hemoglobin level of more than $14 \mathrm{~g} / \mathrm{dL}$. The difference between our data and that of the literature is probably is due to the fact that 300 of the 307 patients examined had hemoglobin levels in the normal range and did not, therefore, receive these agents. Our data are not adequate to allow conclusions to be drawn as to whether VTE is relates to erythropoietin use, and since this possibility can not be excluded it should be validated in specific trials. The results obtained in our study support the usefulness of thromboprophylaxis in ambulatory cancer patients with NSCLC undergoing chemotherapy, particularly those with adenocarcinoma.

The active drugs for VTE are unfractionated heparin, the class of LMWH, fondaparinus (indirect inhibitor of activated factor $\mathrm{Xa}$ ) and vitamin $\mathrm{K}$ antagonist.

The potential role for thromboprophylaxis in patients with advanced NSLC ${ }^{22-28}$ has become evident from data of the PROphylaxis of ThromboEmbolism during CHemoTherapy (PROTECHT) trial. ${ }^{29}$ This study investigated the role of prophylaxis of venous and arterial thromboembolism events in approximately 1100 patients undergoing chemotherapy.

Because thromboprophylaxis can reduce risk of arterial events, it must be remembered that the primary end point of this study was the incidence of venous and arterial events.

The patients enrolled in the trial had different cancer types: $25 \%$ had lung cancer and over $35 \%$ had gastrointestinal cancer. The data reported that LMWHs decrease the relative risk of thromboembolism events by $47 \%$ compared with placebo with few cases of major bleeding.

But the incidence of thromboembolism events in this study was lower than expected: $3.9 \%$ in the placebo group and $2 \%$ in the LMWH group. The pa- tients with lung cancer showed a higher thromboembolism risk and so they enjoyed greater treatment benefit. This evidence is confirmed from an analysis of the combined data of the 279 patients of the PROTECHT trial and the 532 patients of the Thromboembolism Prevention in Cancer-II (TOPIC-2) trial ${ }^{30}$ (total $\mathrm{n}=811$ ). Fifteen events occurred in 467 patients in the LMWH group (3.2\%) and 22 events in 344 patients in the placebo group $(6.4 \%)$, with a relative risk of 0.50 (95\% confidence interval: $0.25-0.95)$. The metaanalysis did not show any survival benefit in the outpatients who received treatment with LMWH.

\section{Conclusions}

In conclusion, we think that prospective controlled trials must be conducted in outpatients with NSCLC.

\section{References}

1. Stein PD, Beemath A, Meyer A, et al. Incidence of venous thromboembolism in patients hospedalized with cancer. Am J Med 2006;119:60-8.

2. Khorana A, Francis CW, Culakova E, et al. Frequency, risk factors and trends for venous thromboembolism among hospedalized cancer patients. Cancer 2007;110: 2339-46.

3. Agnelli G, Bolis G, Capussotti L, et al. A clinical out come based prospective study on venous thromboembolism after cancer surgery: the @RISTOS Project. Ann Surg 2006;243:89-95.

4. Korana A, Streiff MB, Farge D, et al. Venous thromboembolism prophylaxis and treatment in cancer: A consensus statment of Major Guidelines Panels and Call to Action. J Clin Oncol 2009;27:4919-26.

5. Francis CW. Prevention of venous thromboembolism in hospedalized patients with cancer. J Clin Oncol 2009; 27:4874-80.

6. Rodrigues CA, Ferrarotto R, Filho R, et al. Venous thromboembolism and cancer: a systematic review. J Thromb Thrombolysis 2010;30:67-78.

7. Lin J, Wakefield TW, HenKe PK. Risk factors associated with venous thromboembolic events in patients with malignancy. Blood Coagul Fibrinolysis 2006;17: 265-70.

8. Fotopoulou C, duBois, Karavas AN, et al. Incidence of venous thromboembolism in patients with ovarian cancer undergoing platinum/paclitaxel containing first-line chemotherapy: an exploratory analysis by the Arbeitsgemein Scheft Gynaekologische Ovarian Cancer Study Group. J Clin Oncol 2008;26:2683-9.

9. Alcalay A, Wun T, Katri V, et al. Venous thromboembolism in patients with colorectal cancer: incidence and effect on serviva. J Clin Oncol 2006;24:1112-8.

10. Chew HK, Davies AM, Wun T, et al. The incidence of venous thromboembolism among patients with primary lung cancer. J Thromb Haemost 2008;6:601-8.

11. Chew HK, Wun T, Harvey D, et al. Incidence of venous thromboembolism and its effect on survival among pa- 
tients with common cancers. Arch Intern Med 2006; 166:458-64.

12. Numico G, Garrone O, Dongiovanni V, et al. Prospective evaluation of major vascular events in patients with non small cell lung carcinoma treated with cisplatin and gemcitabine. Cancer 2005;103:994-9.

13. Fernandes DD, Louzada ML, Souza CA, et al. Acute aortic thrombosis in patients receiving cisplatin-based chemoterapy. Curr Oncol 2011;97-100.

14. Scappaticci FA, Skillings JR, Holden SN, et al. Arterial thromboembolic events in patients with metastatic carcinoma treated with chemotherapy and bevacizumab. J Natl Cancer Inst 2007;99:1232-9.

15. Khorana AA, Francis CW. Culakova E, et al. Thromboembolism is a leading cause of death in cancer patients receiving outpatient chemotherapy. J Thromb Haemost 2007;5:632-4.

16. Deitcher SR, Comes MP. The risk of venous thromboembolic disease associated with adjuvant hormone therapy for breast carcinoma: a systematic review. Cancer 2004;101:439-49.

17. Verso M, Agnelli G. Venous thromboembolism associated with long-term use of central venous catheters in cancer patients. J Clin Oncol 2003;21:3665-75.

18. Verso M, Agnelli G, Bertoglio S, et al. Enoxaparin for the prevention of venous thromboembolism associated with central vein catheter: a double-blind, placebo-controlled, randomized study in cancer patients. J Clin Oncol 2005;23:4057-62.

19. Lee AY, Levine MN, Butler G, et al. Incidence, risk factors, and outcomes of catheter-related thrombosis in adult patients with cancer. J Clin Oncol 2006;24:1404-8.

20. Bohlius J, Wilson J, Seidenfeld J, et al. Recombinant human erythropoietins and cancer patients: updated meta-analysis of 57 studies including 9353 patients. J Natl Cancer Inst 2006;98:708-14.

21. Westin SN, Skinner EN, Jonsson Punk M, et al. Incidence of symptomatic deep venous thrombosis with epoetin $\alpha$ or darbepoetin $\alpha$ treatment of anemia in patients with ovarian or primary peritoneal cancer. Gynecol Oncol 2007;105:414-7.
22. Gary H, Lyman HD. Thromboprophylaxis with lowmolecular-weight heparin in medical patients with cancer. Cancer 2009;115:5637-50.

23. ENOXACAN Study Group. Efficacy and safety of enoxaparin versus unfractionated heparin for the prevention of deep vein thrombosis in selective cancer trial with venographic assesment. Br J Surg 1997;84:1099-103.

24. Lazo-Langner A, Goss GD, Spaans JN, Rodger MA. The effect of low-molecular-weight heparin on cancer serviva. J Thromb Haemost 2007;5:729-37.

25. American Society of Clinical Oncology. ASCO guideline: recommendations for venous thromboembolism prophylaxis and treatment in patients with cancer. Alexandria, VA: American Society of Clinical Oncology (ASCO); 2012. Available from: http://www.asco. org/institute-quality/asco-guideline-recommendationsvenous-thromboembolism-prophylaxis-and-treatment

26. Sideras K, Schaefer PL, Okuno SH, et al. low-molecular-weight heparin in patients with adevanced cancer: a phase 3 clinical trial. Mayo Clin Proc 2006;81:758-67.

27. Dolovich LR, Ginsberg JS, Douketis JD, et al. A metanalysis comparing low-molecular-weight heparin with unfractionated heparin in the treatment of venous thromboembolism: examining some unanswered questions regarding location of treatment, product type, and dosing frequency. Arch Itern Med 2000;160:181-8.

28. Kearon C, Kahn SR, Agnelli G, et al. Antithrombotic therapy for venous thromboembolic disease. Chest 2008;133:454-545.

29. Agnelli G, Gussoni G, Bianchini C, et al. Nadroparin for the prevention of thromboembolic events in ambulatory patients with metastatic or locally advanced solid cancer receiving chemotherapy: a randomised, placebocontrolled, double-blind study. Lancet Oncol 2009;10: 943-9.

30. Verso M, Agnelli G, Gussoni G, Prevention of thromboembolic events in advanced lung cancer patients receiving chemoterapy: a combined analysis from PROTECHT and TOPIC- 2 studies. J Thromb Haemost 2007;5:OC-MO-018. 